\title{
Poesia Clássica Chinesa - Dinastia Tang: princípios e roteiro de uma antologia em português
}

\author{
Ricardo Primo Portugal
}

\begin{abstract}
Resumo: exposição dos princípios que orientaram a preparação e as traducõos do livro Antologia da Poesia Chinesa - dinastia Tang, no prelo, com descrição dos aspectos estruturais da poesia clássica chinesa, a partir de poemas de Du Fu e Li Bai, desenvolvendo os conceitos de paralelismo, harmonização sonora/ aliteração, tradução-recriação, tradução estrangeirizante e outros, com base em aportes teóricos de Walter Benjamin, Roman Jakobson, Haroldo de Campos, François Cheng e outros autores.
\end{abstract}

Palavras-chave: poesia, dinastia Tang, formas clássicas, paralelismo, harmonização sonora.

Está no prelo a Antologia da Poesia Chinesa - dinastia Tang, livro que é o resultado mais consistente de nossas atividades de estudo e tradução durante os últimos anos. Essa pequena obra, que preparei em coautoria com Tan Xiao, será, muito possivelmente, a primeira antologia poética mais abrangente, publicada em nossa língua, da dinastia Tang (618-907), a "idade de ouro" da literatura chinesa clássica, com textos de mais de 30 autores - a maioria inéditos em português - e mais de 200 poemas.

Com efeito, é forçoso admitir que ainda pouco se fez em língua portuguesa, quanto à tradução de textos literários chineses, em comparação com outras línguas ocidentais. Entre nós, a China mal começa a deixar o terreno da alteridade extravagante, situado entre os polos opostos da aversão etnocêntrica e do deslumbramento com os exotismos do Oriente.

Em poesia, as iniciativas ocorridas até hoje, ainda que significativas - por exemplo, as valiosas coletâneas dos portugueses António Graça de Abreu e Gil de Carvalho, as poucas traduções de Camilo Peçanha, o instigante Escrito sobre jade, de 
Haroldo de Campos, constituíram, em geral, trabalhos isolados, além de serem quer muito genéricas (compilações da "poesia chinesa toda ela" em poucas páginas), quer bastante restritas, isto é, destinadas a um só autor ou a um conjunto muito reduzido de escritores e textos principais. Em português, já no início do século XXI, conta-se quase exclusivamente com coletâneas genéricas e introdutórias.

A tarefa de organizar uma antologia sempre esbarra na questão dos critérios de escolha; ainda mais neste caso, perante um conjunto de autores e obras numeroso e de notória excelência. Pareceu-nos que um primeiro passo importante seria o de avançar para além da apresentação genérica, indiferenciada e global da "poesia clássica chinesa, toda ela". Nesse sentido, a escolha da Dinastia Tang permitiu-nos concentrar a visão no conjunto dos autores e obras que demarcaram o apogeu histórico, o principal centro de referência, da literatura clássica, objeto das principais antologias consagradas em chinês.

\section{As formas e modelos clássicos}

No princípio da dinastia Tang, as pesquisas formais e estudos linguísticos haviam chegado a um elevado grau de refinamento. Seja pelo desenvolvimento próprio da ambiência literária, seja por necessidade dos exames imperiais, que demandavam a sistematização de conteúdos, chegou-se, por essa época, a uma codificação e definição precisa das formas em uso, as quais constituirão os modelos clássicos, predominantes até o advento do modernismo, nas primeiras décadas do século XX.

Para além das formas tradicionais relativamente "livres", em métrica e outros códigos, que se praticavam também na dinastia Tang, a marca específica da literatura dessa época é o chamado Estilo Novo - 近体诗 jintishi -, no qual a forma básica, considerada o fundamento das demais, era o octeto regular, 律诗 lïshi, de métrica fixa em 5 ou 7 sílabas. O quarteto regular, 绝句 jueju, forma em que poetas da relevância de Wang Wei, Du Mu e Meng Haoran foram particularmente prolíficos, era definido como um lïshi cortado, reduzido ou "suspenso". Havia também o changlü (literalmente, "lüshi alongado"), que acrescentava novos versos.

A estrutura do octeto lüshi representa uma unidade semântica e sintática complexa, na qual se verifica a consolidação de séculos de desenvolvimento da poesia e da teoria literária. A unidade mínima do octeto é o dístico, 对联 duilian. Ele é organizado sobre o princípio do paralelismo, que consiste em uma estrutura de dois sintagmas em relação de "espelhamento", em correspondência entre seus elementos constituintes. As classes/funções gramaticais dos versos em paralelismo se correspondem, termo a termo. Apõe-se, assim, uma leitura 
"vertical", paradigmática, que se cruza ou complementa a leitura "horizontal", sintagmática ${ }^{1}$.

A título de exemplo de um dístico paralelo (ou organizado por paralelismo), vejamos os versos a seguir, extraídos de poema de $\mathrm{Du} \mathrm{Fu} \mathrm{"Contemplando} \mathrm{a} \mathrm{grande}$ montanha" (望岳wang yue):

\section{(...)}

\section{荡胸生曾云}

dang xiong sheng ceng yun

dilatado peito/nascem [em] andares nuvens

决䀝入归鸟

jue zi ru gui niao

estendidos olhos/entram [em] retorno pássaros

(...)

\section{Na tradução:}

o peito estende às nuvens que acumulam

olhos distendem pássaros que entram

Note-se a correspondência entre os elementos lexicais (as classes/funções de palavras) do verso superior e do inferior. Impõe-se (ou talvez: sugere-se, revela-se) uma leitura vertical "dilatado-estendido"; "peito-olhos"; "nascem-penetram"; "em andares-em retorno"; "nuvens-pássaros". As palavras do dístico dispõem-se de maneira simétrica, em correspondência paradigmática, estabelecendo entre elas relações de oposição ou de complementaridade. Essa estrutura de correspondências binárias é então trabalhada, no octeto, em pares semânticos de conjunção ou disjunção. O segundo verso traz inaugurações, transformações ou simples oposições aos elementos do primeiro.

No caso desse dístico de $\mathrm{Du} \mathrm{Fu}$, vê-se um recurso adicional de significação, propiciado pelo paralelismo, que é explorado com maestria pelo poeta: a inversão sintática. Isto é: os termos organizam-se simetricamente, mas sua ordem sintática foi alterada. Esse recurso é uma exploração particularmente ousada da metonímia no paralelismo, em uma língua de sintaxe posicional, na qual a ordem dos termos é fundamental para sua função sintática. Estes versos causam grande estranhamento

1 Sobre as noções de eixo paradigmático e eixo sintagmático da linguagem, ver JAKOBSON, Roman, Linguística e comunicação. 
em chinês, como se significassem: "o peito dilatado produz nuvens em camadas/ os olhos distendidos entram nos pássaros que voltam".

O paralelismo é também chamado por alguns autores de "contraponto semântico" (v. DÉMIEVILLE, 1962), metáfora da teoria musical, mas pertinente, na medida em que se trata da superposição, ou justaposição, de significações opostas ou complementares, que "soam juntas", integram-se em um nível superior de significação, em um processo de conotação.

Naturalmente, também a musicalidade, isto é, a harmonização fonética do poema, é um dos instrumentos da linguagem poética em que se apoia o efeito semântico do paralelismo - que, a rigor, é uma espécie de "eco semântico", uma forma codificada de repetição. O poema clássico é sempre rico em aliterações, assonâncias, rimas, onomatopeias e outros recursos sonoros.

O paralelismo acentua o eixo paradigmático em uma leitura que se acresce ou se cruza à do sintagma. Nesse sentido, é um recurso que estabelece interrupções ou pausas na linearidade e discreção essenciais ao signo linguístico (como ensinado por Saussure), alterado no uso da poesia, arte na qual o texto se amplia até a intersecção com as artes plásticas e a música. Em se tratando da poesia chinesa clássica, isso se acentua pela escrita ideogramática, a visualidade, movimento e musicalidade intrínsecos ao caractere chinês.

Para além do conceito geral de paralelismo, considera-se que, no plano sintático, o fato mais importante do octeto clássico chinês é a oposição entre versos paralelos e não-paralelos. Assim, o primeiro dístico é, geralmente, de versos não-paralelos, mas é admissível que sejam paralelos. O segundo e o terceiro dístico são obrigatoriamente construídos em paralelismo e o último é necessariamente de versos não-paralelos.

Têm-se, desta forma, uma estrutura na qual o último dístico e, na maioria dos casos, também o primeiro são afeitos a uma ordem "temporal", isto é: fixam uma moldura de narratividade para o poema. Os dois dísticos paralelos ao centro dispõem uma ordem "espacial", em que um conjunto de signos engendra um outro, contrário ou complementar, através do qual uma instância pictorial-descritiva se impõe, em uma suspensão da progressão temporal-lógica.

Em um dístico paralelo, o primeiro verso se desdobra sem propriamente transitar para o segundo; ele se suspende, para ser confirmado, modificado ou "fechado" pelo segundo. A sensação que se encontra, muitas vezes, em um poema chinês clássico, é de que há segmentos (sintagmas) incompletos, abertos, submetidos a fragmentações e quebras sucessivas. É o eixo paradigmático que se acentua nesses versos. 
Segundo Cheng (1996): "De um ponto de vista linguístico, o paralelismo é uma tentativa de organização espacial dos signos no interior de seu desenvolvimento temporal" (tradução nossa,). Na época dos Tang, a arte do paralelismo chegou a um refinamento extremo, apoiando-se em todos os recursos da língua, para além da organização sintática das palavras: sonoro, gráfico-visual, semântico (o repertório de imagens estereotipadas e inter-referenciadas).

Observemos o exemplo abaixo (白帝 Baid ), também de Du Fu, o mestre maior do lüshi. Construído com versos paralelos já desde o primeiro dístico do qual, aliás, os três primeiros caracteres, quase a metade, são uma repetição rigorosa, a anáfora do locativo "cidade de Baidi" -, este poema é também um exemplo particularmente vívido da utilização de recursos sonoros e visuais em apoio ao paralelismo:

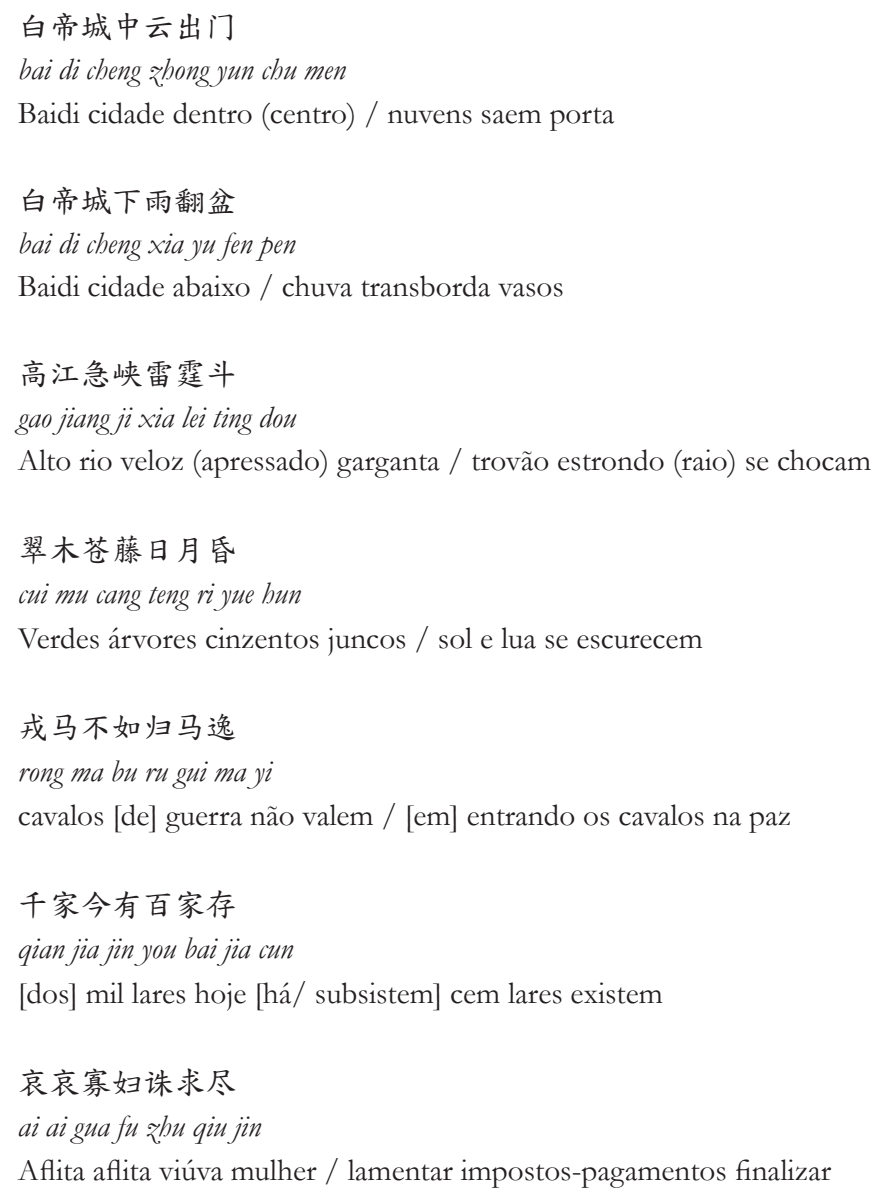


恸哭秋原何处村

tong ku qiu yuan be chu cun

Grito choro o outono na planície / [em] que lugar (é) a vila

Na tradução:

Bai Di ao centro nuvens transbordam os portais

Bai Di abaixo a chuva se derrama à terra

$\mathrm{O}$ rio se abate à gorja trovão raio esbatem-se

o verde e o cinza às ervas lua e sol em trevas

Cavalos desvalidos para a paz à guerra

milhares eram os lares uns cem permanecem

Outono veio à viuvez triste sozinha

o choro estrídulo à planície em qualquer vila

$\mathrm{Na}$ tradução, procuramos reproduzir o paralelismo sintático; porém, considerando a estrutura diferenciada da sintaxe da língua portuguesa, nem sempre isso é possível mantendo-se a tensão poética. Buscamos, então, reconstruir o efeito semântico do paralelismo através, principalmente, de recursos sonoros, apoiando-nos no uso de aliterações e assonâncias, como, aliás, é realizado pelo próprio poeta no original.

Apontemos alguns dados da estrutura fonética e semântica do poema:

1. O primeiro e o segundo versos começam pela anáfora do locativo (Bai Di cidade). Logo em seguida, há uma correspondência paradigmática, superposição 中 下 zhong-xia (centro-abaixo) 云雨yun-yu (nuvem-chuva, também correspondência sonora); 出反 chu-fan (sair-virar); igualmente em men-pen (porta-vaso, também correspondência sonora).

2. No primeiro verso, a palavra 中 z̧ong (centro, meio) está precisamente na quarta sílaba de 7, o centro do verso, dividindo-o em dois hemistíquios - o olho que observa e narra, ao centro de tudo, lugar da enunciação.

3. O verso parte da "solidez" (a cidade com nome imperial e de sons oclusivos; o caractere 城 cheng, que significa "cidade" e "muralha") para a "fluidez". O par 中下 zhong-xia ("centro-embaixo") acentua o significado de queda, desabamento. Os pares 云雨 $y u n-y u$ (nuvem-chuva) chu men-fan pen (sair à porta-virar os vasos) sobrepõem fatos do céu e da terra, "de cima" (ou centro) e "de baixo". Há um sentido geral de queda desde um lugar (centro) muito alto, mas também de fusão entre posições-lugares. 
4. Esse efeito de significação é construído, ainda, por um recurso encontrável na escrita ideogrâmica chinesa: a visualidade dos caracteres, sua estrutura de montagem de radicais visuais-cinésicos-abstratos-sonoros. Um exemplo notável, percorrendo estes dois dísticos: na quinta sílaba, a leitura paradigmática, vertical (percorrendo os versos da estrofe, do primeiro ao quarto, de cima abaixo) será: "nuvem-chuva-trovão" (seguido horizontalmente, no terceiro verso, quarta sílaba, por "clarão ou estrondo" [ting]); "sol”" (também seguido, no quarto verso, quarta e quinta sílabas, de "lua-escurecimento"). Esta sucessão, que se dá verticalmente, mas que parece transbordar para leituras horizontais parciais, é melhor visível em caracteres tradicionais: 雲 yun-雨 yu-雷 lei (霆 ting); 日 ri (月 yue - 昏 hun). O caractere para chuva (雨 yu), o segundo da sucessão (雨 yu), está presente na composição do primeiro, o terceiro e o quarto, todos fenômenos atmosféricos correlatos, dando um efeito de continuidade e variação à sucessão. Ainda, ao final, "escurecimento" (昏 hun) tem, em sua base, “sol, calor, luz” (日 $r$ ). Como já se disse, “o que o "poeta concreto' contemporâneo empenha-se em realizar é precisamente o que muitos poetas chineses tradicionais efetuaram naturalmente por séculos". ${ }^{2}$

5. Nos dois primeiros versos: os fones /yu/ (ü) e /u/ ecoam três vezes. Há um uso farto de consoantes fricativas $(/ \mathrm{ch} /, / \mathrm{zh} /, / \mathrm{x} /)$ a partir das oclusivas $(/ \mathrm{b} /, / \mathrm{d} /)$, que iniciam o segmento, e o terminam em $/ \mathrm{p} /$ (en).

6. No segundo dístico (terceiro e quarto versos), as oposições paradigmáticas são: alto-verdes, rio-árvores, veloz(apressado)-cinzentas, garganta-juncos, trovão-sol, estrondo (raio, clarão)-lua, chocam-escurecem. A estrutura sonora prioriza consoantes oclusivas. Os pares paradigmáticos constroem sentidos de confusão-superposição entre claro e escuro; baixo e alto; luz/sombra/escurecimento; lugares largos e lugares estreitos/fechados; ruído e luminosidade (sinestesias) cores e sombras. Há a admirável sequência "gao-jiang-ji-xia" (alto-rio-rápido-cair para baixo) no terceiro verso, cuja visualidade se constrói através da sonoridade, pelas aliterações e assonâncias. O quarto verso é mais suave sonoramente,

7. O efeito geral da estrofe é de desabamento e choque violento entre forças naturais, a confusão e o deslocamento de lugares entre os elementos. A chuva forte se mescla à violência do rio que se apressa à garganta. A grandiosidade suave e mais lenta do verso final, com o escurecimento da lua e do sol, parece reproduzir um cataclismo, antecipando em metáfora a estrofe seguinte, sobre a tragédia da guerra.

2 Eugene Eoyang, apud Haroldo de Campos, "A Torre do Grou Amarelo de Li Po a Mao Tse-Tung", in Escrito sobre Jade. 
Na tradução destes dois dísticos (bem como no restante do poema), procuramos construir o efeito do paralelismo da estrofe chinesa por aliterações e assonâncias, com repetições sonoras em ecos e onomatopeias nos quatro versos (transbordam-portais; derrama-terra; abate-esbatem-se; verde-ervas-trevas). Percorrem toda a estrofe, em repetição, os sons (/pa/, /ba/, /rr/, /tr/, /er/, /ra/):

\section{Outros aspectos a observar na tradução}

Para além do princípio sintático-semântico-fonético do paralelismo, outros aspectos gerais do poema clássico chinês são desafios que se colocam para os tradutores:

1. Métrica, esquema sonoro e visual: a poesia clássica chinesa segue esquemas sonoros complexos. A métrica, no jintishi, é regular, em 5 ou 7 sílabas, o que, em nossas traduções, vertemos para, em geral 10 ou 12 sílabas, conforme a versificação clássica portuguesa. Há estruturas padronizadas quanto a rima de final de verso (sempre a mesma rima percorre um poema, em versos alternados, em primeiro tom), padrões tonais (a língua é tonal, o que também é um recurso incorporado na poesia); esquema visual (propiciado pela visualidade dos caracteres chineses), em uma estrutura geral de intensa aliteração e assonância. Quanto à rima, procuramos soluções mais chegadas à tradição da língua portuguesa, mas optamos, talvez na maioria dos casos, pelas rimas toantes. Essa escolha é estilisticamente mais contemporânea do que, em geral, as rimas consoantes e, simultaneamente, mais assemelhada ao esquema sonoro do poema chinês clássico.

2. Aspectos semântico-lexicais - supressão das palavras vażias: na poesia clássica chinesa, sobretudo no jintishi (Estilo Novo), pratica-se um código de supressão das palavras vazias (conceito gramatical referente a nexos, conexões, pronomes) e a ênfase às palavras cheias (nomes e verbos ativos). Um efeito significativo dessa regra é o deslocamento do "eu-lírico" e a instauração de uma "objetivação" da linguagem. Ainda que, no chinês, a supressão do pronome pessoal seja mais frequente que no português, mesmo na fala corrente, na poesia clássica trata-se de um código estrito, utilizado de maneira especial, que instaura um ambiente linguístico "artificial", distante do uso "natural". Esse modelo deixou marcas na poesia de países cujas culturas foram influenciadas pela China, em especial pela dinastia Tang - por exemplo, a objetividade do hai-cai japonês lhe é tributária. A objetivação do texto pelo deslocamento, ou não-explicitação, do "eu-lírico" é também um recurso presente na poesia contemporânea ocidental e brasileira, o qual procuramos ter como parâmetro na maioria de nossas traduções. 
3. Aspectos semântico-lexicais - repetições: em chinês, inclusive na fala do dia a dia, é comum a repetição de vocábulos, por sentido de ênfase ou aproximação afetiva. A repetição vocabular também é uma das formas do diminutivo (por exemplo: uma criança pequena poderá referir-se a seu “pezinho" como 脚脚 jiao-jiao). O recurso à repetição é muito usado em poesia; em paralelismo, é comum a sobreposição de versos com elementos repetidos na mesma posição sintática. As repetições também têm uma função sonora, de onomatopeia. Nesses casos, procuramos, por vezes, mantê-las na tradução para o português, mas alterando ou trabalhando ambiguidades sintáticas. Por exemplo, no poema de Li Bai - "Canto antigo - do alto contemplar os quatro mares...”(古风・登高望四海-gu feng - deng gao wang si hal):

\author{
登高望四海 \\ deng gao wang si hai \\ subir alto contemplar quatro mares \\ 天 地 何漫漫 \\ tian di be man man \\ céu terra (mundo) como (é) vasto vasto \\ 霜 被 群物 秋 \\ shuang bei qun wu qiu \\ geada lençol multitude coisas outono
}

风飘大荒寒

feng piao da buang han

vento sopra grande deserto frio

(...)

Na tradução:

do alto contemplar os quatro mares

céu-terra o mundo inteiro vasto o vasto

lençol de gelo o outono este tecido

lufar do vento ao mais deserto frio

Em outros casos, procuramos representar a repetição do original por recursos de semelhança sonora; por exemplo, no poema abaixo, de Du Fu, "Desde um alto terraço" (登高 - deng gao): 


\title{
风急天高猿啸哀
}

feng ji tian gao yuan xiao ai

vento apressado céu alto macacos gritam em luto

渚清沙白鸟飞回

zhu qing sha bai niao fei bui

ilhota pura areia branca pássaros voam retornando

\author{
无边落木萧萧下 \\ wu bian luo mu xiao xiao xia \\ sem limite caindo árvores desoladas desoladas cair
}

\section{不尽长江滚滚来}

bu jin Chang juang gun gun lai

inesgotável longo rio rolando rolando vem

$(\ldots)$

Note-se a riqueza das aliterações; no terceiro verso, a repetição do caractere 萧 xiao ecoa no último, 下 xia, o conjunto funcionando como onomatopeias das folhas das árvores caindo sopradas pelo vento. No último verso, a repetição de 滚 gun, ecoada pelo começo em 不 bu e pelas nasalizações (n, ang) de outros caracteres, imita o movimento rápido e desordenado, o "rolar" do rio. No original chinês, portanto, as repetições se fundem ao ambiente geral das aliterações; isto é: a reduplicação sonora ecoa a semântica.

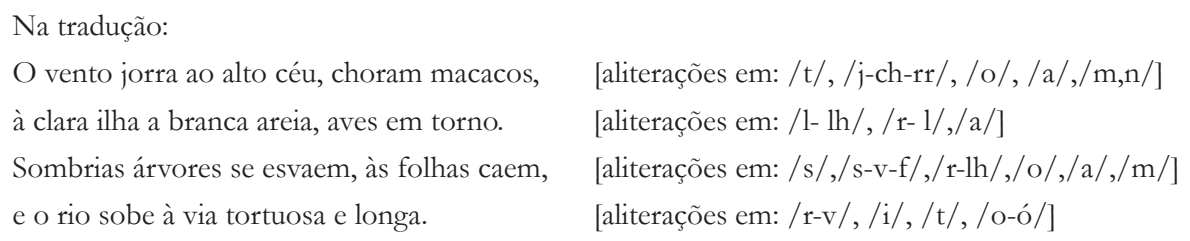

4. Aspectos semânticos - metáforas estereotipadas: há uma repetição de metáforas reconhecidas na tradição - salgueiros como tristeza da despedida; patos-mandarins como signo do amor conjugal para toda a vida; gansos e peixes como mensageiros, e outras.

5. Aspectos semânticos - intertextualidade: mesmo o chinês falado no dia-a-dia faz recurso à intertextualidade, em uma linguagem cheia de citações, referências 
a episódios históricos e fórmulas estereotipadas. Os poetas clássicos citam-se uns aos outros, além de a filósofos, intelectuais notáveis e episódios históricos. O recurso a referências é particularmente utilizado por Li Shangyin, Li He, Wen Tingyun, Yu Xuanji e outros poetas do período final da dinastia Tang, o que é, inclusive, objeto de artigos acadêmicos. A opção por, simplesmente, suprimir essas referências seria empobrecedora, pois elas, por vezes, abrem para significações importantes e até necessárias para a compreensão de poemas - há textos cujo objeto é um episódio histórico, por exemplo.

O uso de notas de rodapé, portanto, foi indispensável. Mas também foi mais conveniente fazermos, em alguns casos, a opção pela reconstrução do efeito poético do original, contornando a referência intertextual levantada pelo poeta, ou então trabalhando referências dentro do universo cultural e literário do Brasil e da tradição poética da língua portuguesa e da cultura ocidental.

6. Pontuação: o texto original dos poemas, em caracteres chineses tradicionais, raramente se utilizava de pontuação. As pausas e modulações eram evidentes a partir do próprio texto. A frase interrogativa, por exemplo, evidenciava-se pelo contexto, pela distribuição gráfica e pela utilização de vocábulos de função interrogativa. Essa particularidade da escrita chinesa antiga parece atualizar-se na utilização contemporânea da pontuação em poesia, que se utiliza de códigos diferenciados, isto é, para cada poema, cria-se um código de pontuação que lhe seja estruturalmente mais apropriado. Assim, para as traduções em português, utilizamos uma codificação contemporânea de pontuações variadas, que foram desde a ausência completa de qualquer marca de pontuação - e de letras maiúsculas -, acentuando certa imprecisão sintática do texto, até a pontuação portuguesa convencional completa, passando por códigos intermediários.

\section{Traduzir-recriar poesia clássica chinesa}

Há, portanto, desafios específicos na tradução da poesia clássica chinesa colocados por características da língua e pelo alto grau de codificação das formas. Muitos recursos dessa poesia, que se apoia em uma linguagem de possibilidades simbólicas inexistentes em línguas ocidentais, são virtualmente intraduzíveis em si mesmos. Trata-se, contudo, de buscar recriar o efeito desses textos pela utilização de recursos sonoros e semânticos de nossa língua.

Sobretudo, evitar que o texto soe "normal", facilmente reconhecível como poesia de nossa cultura, o que frequentemente acaba dando em diluição em favor de um modelo considerado mais ou menos "equilibrado" ou assimilável por um hipotético "leitor médio". Por exemplo: traduções de poesia chinesa de alguns 
eminentes sinólogos ingleses do final do século XIX foram criticadas por poetas "imagistas" norte-americanos (Ezra Pound, Amy Lowel) e por analistas mais recentes pela semelhança com o texto poético convencional da era vitoriana.

A tradução "fácil" é uma tentação perigosa, talvez ainda mais hoje em dia, quando certo Modernismo simplificou e, aparentemente, "democratizou" a arte da poesia e da versificação, fixando a linguagem coloquial e o verso "livre" como princípios estruturais universais. Encontram-se frequentemente - sobretudo em língua inglesa, o idioma em que há maior quantidade de traduções disponíveis, e há mais tempo - traduções "modernizantes", que contornam a especificidade e complexidade do texto clássico chinês na produção de peças "líricas" (que apresentam e tentam expressar um "eu lírico"), algo distanciado dos poemas originais pretendidos.

A sensação causada por essa espécie de tradução pode ser bastante "estranha", principalmente quando se trata dos textos de um mestre como Du Fu, cuja poesia é extremamente codificada, com grande virtuosismo no uso dos recursos formais. Seria o equivalente, para o leitor culto do português ou do inglês, a encontrar sonetos de Camões ou Shakespeare traduzidos para o chinês em versos livres, em transcrição literal, sem recursos sonoros, rimas e aliterações...

Veja-se, a propósito, o "desabafo" de um mestre da tradução chinesa em inglês, Wai-lim Yip:

'Wrong from the start!'. Borrowing a phrase from Pound's critique of the decline of English poetic art, in 1960 I protested in dismay and anger against a century of gross distortions of Chinese poetry by translators who allowed the target language (in this case, English) to mask and master the indigenous Chinese aesthetic, creating treacherous modes of representation (...). [Prefácio a Chinese poetry]

No caso da poesia clássica chinesa, temos formas codificadas, não "naturais", em geral bastante dissociadas da linguagem coloquial, reproduzidas por milhares de poetas, construídas e refinadas no decorrer de uma tradição extensa. Sua tradução para o português de hoje dará em poemas modernos, mas que deverão incorporar uma leitura do classicismo chinês - o que poderá conduzir, ainda, a uma leitura comparativa do classicismo ocidental, brasileiro-português.

Buscamos uma recriação do texto chinês que seja estrangeirizante do texto resultante em português (ver o conceito de foreignizing translation exposto por Froula (2003)). O poema estrangeiro amplia o repertório de minha língua; expande, modifica, discute as possibilidades textuais de minha língua; propõe uma releitura e reescrita da minha tradição, desde o exterior. O poema estrangeiro deve 
ser traduzido como trazendo algo novo a minha língua, para além da reiteração do conhecido. Ou, conforme a fórmula feliz de Haroldo de Campos: "tradução é a inscrição de um outro dentro do mesmo".

Assim a tradução não será encarada como o "aportuguesamento-abrasileiramento" do poema estrangeiro, proposta que tenderia a cair na falácia de seguir uma "ficção de leitor", como sugere Walter Benjamin ("A tarefa do tradutor", in Escritos sobre mito e linguagem). Na descrição do filósofo alemão Rudolf Pannwitz, apud Benjamin, “(...) o erro fundamental de quem traduz é conservar o estado fortuito de sua própria língua, ao invés de deixar-se abalar violentamente pela língua estrangeira (...)" [idem.].

Não é possível realizar uma tradução poética que recupere minimamente o efeito do original apenas com a reprodução do conteúdo, sem consciência de linguagem em relação à forma. Construído por conotação, em texto densificado pelo jogo de metáforas e metonímias, pelo trabalho artístico sobre o significante, o significado poético estará, muitas vezes, "além do texto", dos conteúdos expressos.

Segundo Roman Jakobson:

(...) em poesia, as equações verbais são elevadas à categoria de princípio construtivo do texto. As categorias sintáticas e morfológicas, as raízes, of afixos, os fonemas e seus componentes (...) transmitem assim uma significação própria. A semelhança fonológica é sentida como um parentesco semântico. (...) A poesia, por definição, é intraduzível. Só é possível a transposição criativa: transposição intralingual - de uma forma poética a outra -, transposição interlingual ou, finalmente, transposição inter-semiótica - de um sistema de signos par outro, por exemplo, da arte verbal para a música, a dança, o cinema ou a pintura. [1989].

A impossibilidade da tradução apenas conteudística do texto poético fica mais evidente quando se trata de poesia chinesa, pela radical diferença de estrutura do idioma em relação à dos ocidentais. A linguagem chinesa é baseada no caractere, o sinograma, ideogrâmico e sintético. Ao contrário da língua ocidental - na qual a escrita é, sobretudo, a reprodução fonética da fala, o texto escrito chinês se realiza na síntese ideológica, cinésica (referente a movimento, no caso a dança, pela caligrafia (cf. PORTUGAL, "A dança dos caracteres chineses") e sonora do caractere, que pode sintetizar frases inteiras e representar contextos em uma sílaba, em acumulações de processos metafóricos.

A escrita chinesa é, em si mesma, um sistema intersemiótico, trazendo recursos poéticos desconhecidos no Ocidente. Ainda que admitindo o interesse de propostas de tradução intersemiótica, consideramos o código escrito-fonético da 
língua portuguesa como veículo prioritário para a tradução. Mas na medida em que a tradução trabalhe nos recursos sonoros e imagísticos da língua: se a poesia já é, por si, um texto "artificial", distanciado do uso coloquial, tratar-se-ia de apoiar a tradução sobre a "artificialidade" ("estranhamento", conforme o conceito cunhado pelos "Formalistas Russos") da linguagem poética, a sua alteração em relação ao uso comum diário, a partir dos recursos que nossa tradição abriga quanto às possibilidades icônicas do poema português escrito.

\section{Referências}

ABREU, António Graça de. Poemas de Bai Juyi. Macau: Instituto Cultural de Macau, 1991. Poemas de Li Bai. Macau: Instituto Cultural de Macau, 1996. 2. ed. Poemas de Wang Wei. Macau: Instituto Cultural de Macau, 1993.

BENJAMIN, Walter. "A tarefa do tradutor", in Escritos sobre mito e linguagem. São Paulo: Duas Cidades-Editora 34, 2011.

CAMPOS, Haroldo. Escrito sobre jade. Poesia clássica chinesa reimaginada. Ouro Preto: Tipografia do fundo de Ouro Preto, 1996. Escrito sobre jade. Poesia clássica chinesa reimaginada. Cotia: Ateliê editorial. 2009. O arco-íris branco. Rio de Janeiro: Imago, 1997.

CAPPARELLI, Sérgio; SUN, Yuqi. Poemas clássicos chineses. Porto Alegre: L\&PM, 2012.

CARVALHO, Gil de. Uma antologia de poesia chinesa. Lisboa: Assírio e Alvim, 1989.

CHENG, François. L’écriture poétique chinoise. Paris: Éditions du Seuil, 1996.

DEMIÉVILLE, Paul. Anthologie de la poésie chinoise classique. Paris: Gallimard, 1962.

FROULA, Christine. "The beauties of mistranslation: on Pound's English after Cathay". In: QIAN, Zhaoming (org.). Ezra Pound and China. Ann Arbor: University of Michigan Press, 2003, pp. 49-71.

JAKOBSON, Roman. Linguistica e comunicação. São Paulo: Cultrix, 2007.

MINFORD, John; LAU, Joseph S.M. (org.) Classical Chinese Literature: an anthology of translations from antiquity to the Tang Dynasty v. 1. Nova Iorque: Columbia University Press, 2000. PEÇANHA, Camilo. China - estudos e traducões. Lisboa: Vega, 1993.

PORTUGAL, Ricardo Primo. "A dança da poesia - uma semiótica do caractere chinês". Página eletrônica: http:/ / www.sibila.com.br/index.php/critica/1902-a-danca-da-poesia-uma-semiotica-do-caractere-chines. Acesso em 20 de fevereiro de 2013.

"Poesia completa de Yu Xuanji”. (Entrevista a Ronald Augusto). Página Eletrônica: http://www.sibila.com.br/index.php/critica/1867-poesia-completa-de-yu-xuanji. Acesso em 20 de fevereiro de 2013.

QIAN, Zhaoming (org.). Eqra Pound and China. Ann Arbor (MI): University of Michigan Press, 2003. 
YAO, Feng. "Encontro de línguas: os desafios da tradução". In: BONVICINO, Regis; YAO, Feng. Um barco remenda o mar. Dę poetas chineses contemporâneos. São Paulo: Martins Fontes, 2007.

YIP, Wai-lin. Chinese poetry. An anthology of major modes and genres. Durham e Londres: Duke University Press, 1997.

YU, Xuanji. Poesia completa de Yu Xuanji, tradução, organização, prefácio e notas de Ricardo Primo Portugal e Tan Xiao. São Paulo: UNESP, 2011. 